\title{
The Development of Ground Penetrating Radar (GPR) Data Processing
}

\author{
Baso Maruddani and Efri Sandi
}

\begin{abstract}
Ground Penetrating Radar (GPR) is one of radar types that is often used to determine conditions inside or below some surface. GPR is also commonly used as a material evaluation tool by its trait as a non-destructive testing (NDT). One of the most important sections of GPR is signal processing system or GPR data processing that will filter all of the GPR survey results. Reflection signals gained by the radar antenna are then filtered to discover any objects located below the ground surface. The better the process in filtering data, the more accurate the GPR interprets the gained signal. This study aims to design a GPR data processing system that is sufficiently be able to interpret the gained signal so that it can accurately discover any objects located on the ground. This GPR data processing system is expected to work on a variety of frequencies and the application can be developed in various types. The aims of this study are designing and modifying the GPR data processing system.
\end{abstract}

Index Terms-GPR, processing, dewow, filtering, gain.

\section{INTRODUCTION}

Applications for wireless communication systems vary greatly. Radar is one of the applications where the transmitter and receiver are in the same place. Ground Penetrating Radar (GPR) is a wireless communication system that is used to view any objects located under the ground surface or behind the walls. GPR can "view" through the ground by sending electromagnetic signals to a certain object and then gaining a reflection signal from the signal sent earlier and reconstructing that reflected signal. Reflected signals is reconstructed by processing the reflected signals to be an image. GPR design highly depends on the application used. Therefore, GPR to "view" the inner surface is basically different from GPR to observe the shallow surface [1].

GPR has very wide applications, including for geology, archeology, civil engineering, non-destructive testing (NDT) and in the field of defense and security. Several studies have been conducted on GPR. Both from the hardware side, namely the antenna, and from the software side [2]. On the hardware side, research that has been conducted was about the selection of the GPR working frequency. The choice of antenna working frequency used in GPR devices depends on the application used, because each antenna has a radiation pattern and some characteristics will affect the final

Manuscript received July 17, 2019; revised October 15, 2019. This research is partially supported by Institute of Research and Community Service, Universitas Negeri Jakarta and DJA Institute Jakarta, Indonesia.

Baso Maruddani and Efri Sandi are with the Faculty of Engineering, Univeritas Negeri Jakarta, DKI Jakarta, Indonesia. Baso Maruddani is also with DJA Institute, DKI Jakarta, Indonesia (e-mail: basomaruddani@unj.ac.id, efri.sandi@unj.ac.id). interpretation of the GPR readings results [3]. Several studies have been conducted in [4]-[6] to improve the accuracy of the GPR reading results system and the development of the antenna model used. The antenna design has also been compared comprehensively in [7]. Explained in [7] that the antenna working frequency, antenna gain and antenna impedance were tested to determine the compatibility with the GPR application that was implemented.

The research on GPR data processing has been conducted in [2], [8]-[13]. In [2], software for GPR data processing from $\mathrm{R}$ - language was created, called RGPR. RGPR is built based on two classes to filter and visualize GPR data by paying attention to step by step data filtering process. There are many basic methods of GPR data processing which are implemented in the RGPR. However, the RGPR is still under development and improvement at this present. One of the methods that used in RGPR is as stated in [14].

\section{The PrinciPles AND Signal MEASUREMENT OF GPR}

Every material has electrical properties which those properties are important for knowing. Those properties are permittivity $(\varepsilon)$, conductivity $(\sigma)$ and permeability $(\mu)$. In GPR application, value of permittivity and conductivity is important while permeability is rare of concern. GPR is most useful if used in low electrical loss materials. If conductivity $(\sigma)$ is zero, then GPR can be see under surface deeper. In reality, low electrical loss materials are not prevalent. Water under surface or moist material or clay rich environment makes the capability of GPR to penetrate the deeper surface is limited. Ground materials are composites from many materials. Ice and water are examples that represent a most case.

In practice, the problem of low electricity losses is not uncommon. An environment that rich in groundwater or saline can create conditions where GPR signal penetration is very limited. Earth material is a combination of many other ingredients or components. Water and ice represent several cases where one main component exists. Simple beach sand is a mixture of soil grains, air, air, and dissolves in the air Ground grains will usually be placed $60-80 \%$ of the available volume. Understanding the physical nature of the mixture is a key factor in the interpretation of the GPR response. A mixture of materials that rarely shows properties proportional to the volume fraction of its constituent components. In many cases, this can make quantitative analysis impossible without additional information.

How GPR works is conceptually simple. Its aim is to measure the amplitude of signal and time after excitation. 
The core of the GPR system is a time management unit which regulates the signal generating and detects signal echo as shown in Fig. 1. Most of GPR is works in time domain so that to synthesize time domain responses, frequency domain is used.

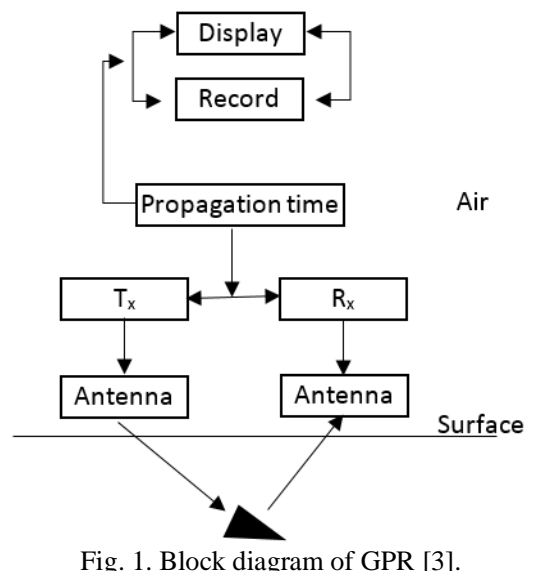

Fig. 1. Block diagram of GPR [3].

Characterization of radar systems is a complex assigment because there are many problems that affect the operation and use of the system. Electronic instrumentation factors that govern the characterization of GPR are signal generation, signal processsing, signal capture methods, dynamic range, performance factors, center frequency and bandwidth, support, and portability. The antenna converts the electrical signal from and to the electromagnetic field.

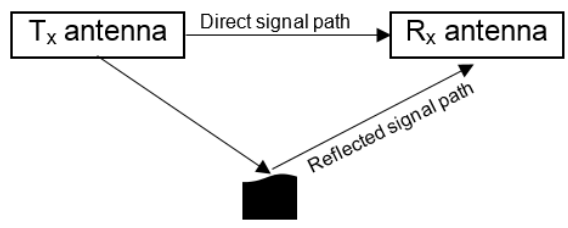

$$
\begin{aligned}
\Delta t=\frac{\text { Direct signal path }- \text { Reflected signal path }}{V} & \\
=\frac{\Delta \text { Length }}{V} &
\end{aligned}
$$

Fig. 2. Transmitter blanking that occurs because overlapping between direct signal and reflected signal [3].

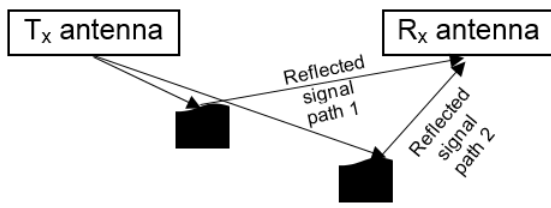

$$
\begin{array}{r}
\Delta t=\frac{\text { Reflected signal path } 2-\text { Reflected signal path } 1}{V} \\
=\frac{\Delta \text { Length }}{V}
\end{array}
$$

Fig. 3. Transmitter blanking that occurs because overlapping between two reflected signals that have a similar path length [3].

The GPR system has to record the data with an accuration of time which less than 10 ps for 10,000 ns duration [3]. Bandwidth measurement depends on the application and is directly related to resolution. The resolution of two topics related to "transmitter blanking" and "target separation" is illustrated in Fig. 2 and Fig. 3.

The transmitter blanking is caused by the inability of the receiver to detect the signal until the transmitter has finished transmitting. Transmitter blanking occurs when the directsignal from the transmitting antenna that propagates to the receiving antenna overlaps with reflected signals from objects below the surface

This is bandwidth and dynamic range problem. The transmitter source usually emits a very large signal, and if the receiver is near the cassing transmitter in GPR, the receiver will see a very large direct signal transmitted. If this signal is large enough, the electronic receiver will be excess and will not receive the reflected signal. The duration of signal propagation time changes inversely with bandwidth. Resolution length $\Delta r$ related to bandwith is

\section{THE CONCEPT OF GPR DATA PROCESSING DEVELOPMENT}

This study aims to develop a GPR data processing, which is expected to be used freely. The development phase of GPR data processing is briefly explained in the Fig. 4.

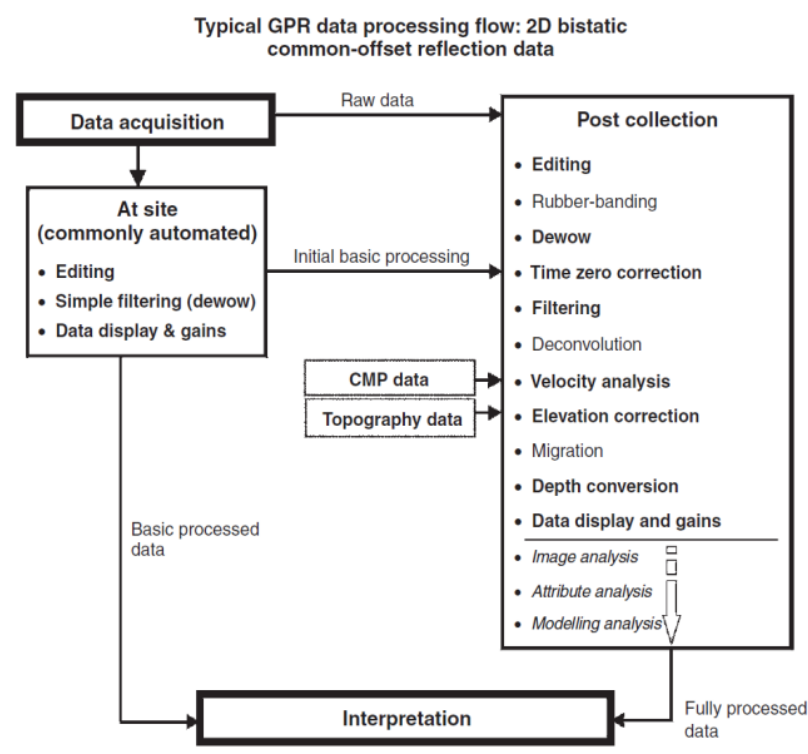

Fig. 4. GPR data processing and analysis steps as explain in [3].

As explained in [3], the editing and rubber-banding phases are the stages of preparing survey GPR data that will be processed. Information about the frequency used, the distance between lines, the number of lines, the number of traces, the type of file used and the others are things that must be known from the beginning so that the data processing in the next step is not wrong. The dewow phase is the stage that aims to eliminate the low frequency and DC bias in the data. Wow is a noise that has a very low frequency value, this occurs due to an electronic instrument saturated by the value of large amplitude of direct waves and air waves. Dewowing is a vital step as it reduces the data to a mean zero level and, therefore, allows positive-negative colour filling to be used in the recorded traces [3]. If done with incorrectly way, the data will be decayed and the low frequency component will distort the spectrum from trace data. This incorrectly processed data will affect to the next data processing stage. If this process is done manually step by step, it is better to eliminate the DC component first and then implement the filter. The dewow concept can be seen in Fig. 5. 


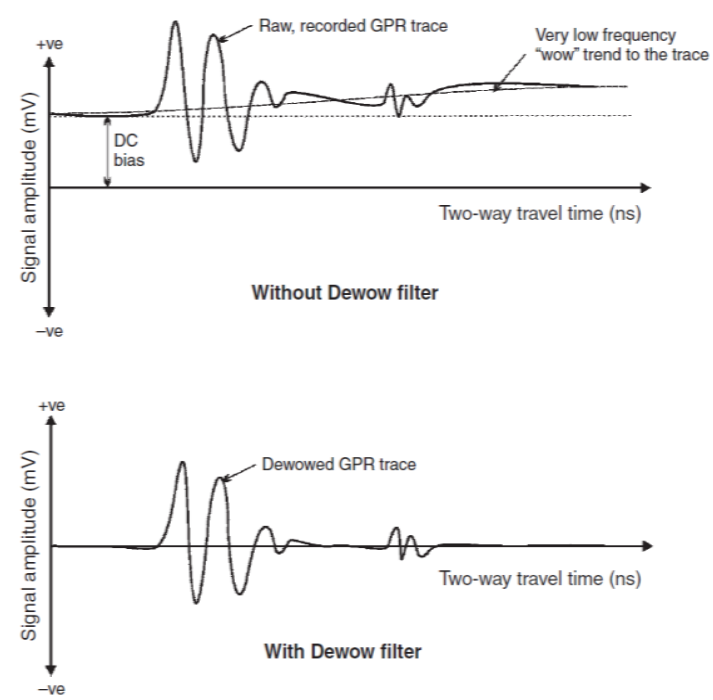

Fig. 5. Dewow concept stage for processing GPR data [3].

The next phase is time zero correction. This aimed to correct the initial time to be exactly the same with the surface of the ground. Thermal drift, electronic instability, cable length differences and variations in antenna airgap can cause 'jumps' in the air/ground wavelet first arrival time [3]. The next phase is filtering, which is done by implementing 1D and 2D filtering to improve signal to noise ratio and correcting image quality. There are many types of filters that can be applied at this phase, from simple band-pass filters to transform filters. Simple filters sometimes effective to eliminate the high frequency noise and low frequencies. And sometimes some complex filters are not needed. In general, filters can be divided into two types, which are temporal (one by one filtering the trace data) and spatial (filter for some trace data). Examples of temporal filters are simple mean, simple median, low pass, high pass and band pass. Examples of spatial filters are simple running average, average subtraction, both background removal and spatial low, high and bandpass filter.

The next stage is deconvolution. Deconvolution aims to contrast signals for increasing the resolution by compressing GPR wavelet data into a narrow band. The purpose is to remove the effect of the source wavelet from the GPR data and leave the impulse response to subsurface layers. This deconvolution process assumes that the subsurface is horizontally layered and has a uniform intra-layer velocity and the signal reflection appears an interface coherently.

The next step is velocity analysis. The purpose of this velocity analysis is to analyze the speed of the GPR signal. Electromagnetic signals are propagating in a medium which depend on the characteristics of the media itself. If in the air, the velocity of electromagnetic waves is $3.108 \mathrm{~m} / \mathrm{s}$. If other than air, the velocity of the electromagnetic wave is smaller than that value. Table I summarizes the electromagnetic wave velocity on certain media.

The next step is elevation correction and migration. The purpose of this step is to correct the effects of topography and the effects of geometry survey also the effects of the spatial distribution energy. The next step is depth conversion. This step synchronizes between two-way travel time and depth. As explained in the Table I, the depth of a surface can be converted from electromagnetic wave velocity and twoway travel time.
TABLE I: APPROXIMATE DielECTRIC PERMITTIVITIES, EleCtRICAL CONDUCTIVITIES AND RADIOWAVE VELOCITIES FOR VARIOUS MATERIALS

\begin{tabular}{cccc}
\hline Material & $\begin{array}{c}\text { Relative } \\
\text { Permittivity }\end{array}$ & $\begin{array}{c}\text { Conductivity } \\
(\mathbf{m S} / \mathbf{m})\end{array}$ & $\begin{array}{c}\text { Average } \\
\text { Velocity }(\mathbf{m} / \mathbf{n s})\end{array}$ \\
\hline Air & 1 & 0 & 0.3 \\
\hline Fresh Water & 80 & 0.5 & 0.033 \\
\hline Sea Water & 80 & 3000 & 0.01 \\
\hline Ice & $3-4$ & 0.01 & 0.16 \\
\hline Dry Sand & $3-5$ & 0.01 & 0.15 \\
\hline Saturated Sand & $20-30$ & $0.1-1$ & 0.06 \\
\hline Limestone & $4-8$ & $0.5-2$ & 0.12 \\
\hline Shales & $5-15$ & $1-100$ & 0.09 \\
\hline Silts & $5-30$ & $1-100$ & 0.07 \\
\hline Clays & $5-40$ & $2-1000$ & 0.06 \\
\hline Granite & $4-6$ & $0.01-1$ & 0.13 \\
\hline Anhydrites & $3-4$ & $0.01-1$ & 0.13 \\
\hline
\end{tabular}

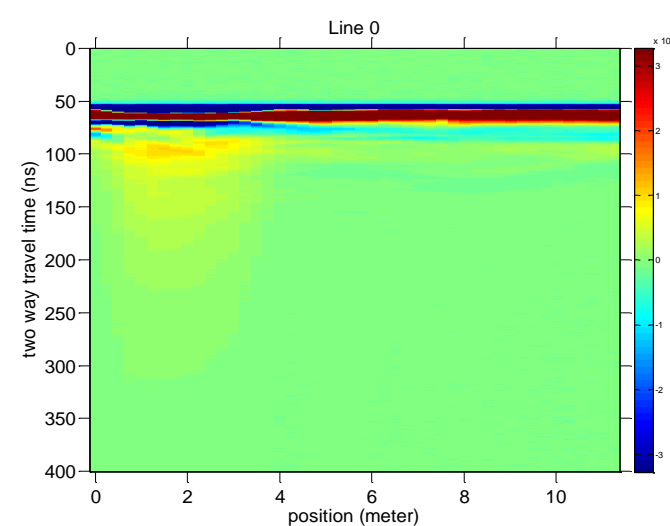

Fig. 6. Image profile of GPR data before being processed for the 0th row data.

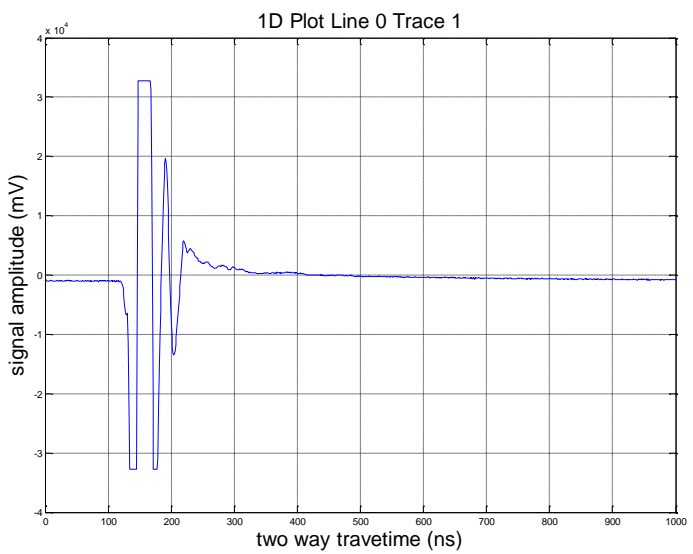

Fig. 7. 1D plot signal trace.

\section{DESIGN AND DisCUSSION OF GPR DATA PROCESSING PROGRAM}

\section{A. Data Preparation Process}

At the first time, the data processing program must be initiated first. GPR data must be stored in a specified folder so that the program created can directly accesses to the data in the previously defined folder. The data used in this study are data in [2]. The format of existing data that will be processed is a data in matrix format which the data characteristics defined in the program are:

- frequency

- the distance between the transmitter and the receiver antenna

- number of rows and number of trace 
- distance between lines (in meters)

- GPR data storage folder

- GPR post processing data storage folder

There is a survey parameter which plays an important role in this program. For each data that will be processed or filtered, this survey parameter must be arranged as organized as possible to be able to process the GPR data. On the GPR data processing program that has been created before, the bottom line is defined at the beginning of the survey parameters on the bottom row. The survey parameter is set to call GPR data in Line00.DT1 format. And then, the program that has been created will call the other GPR data files. The GPR data which tested in this program is a data with four lines of GPR data. Then from the tested GPR data profile, the distance for each rows is 0.2 meters. The distance between the transmitting and the receiver antenna is 1 meter. After all the DSP programs have been set up, then the program is started. The profile condition is under the surface when the program is running and 1D plot consecutive signal amplitude shown in Fig. 6 and Fig. 7.

In Fig. 6 and Fig. 7, it can be seen that GPR scans a surface profile where the condition of the GPR antenna does not exactly touch the ground, so it appears in the image an area where EM signals from GPR propagate in the air before entering the ground.

\section{B. Data Filtering Process}

Dewow Process and Time Zero Correction: In Fig. 6 above, there is no known information related to the unprocessed survey GPR data. Therefore, processing is extremely needed for the GPR data. In processing GPR data, the first thing to do is to return the signal to the actual position, because there is a pause time when the data is released at the time of data acquisition on the field. The time-zero correction process is performed to eliminate the signal pauses.

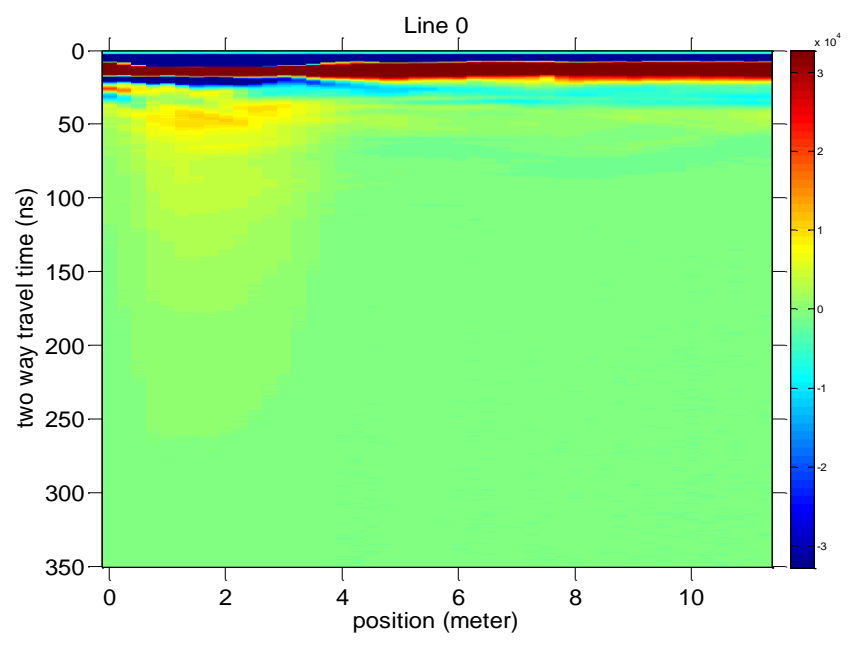

Fig. 8. GPR data image after time zero correction.

Fig. 8 presents the profile of GPR data after time zero correction. In this time zero correction process, the calculation of the frequency, wave propagation time between the transmitter antenna and receiver antenna, and then eliminates the amplitude value of the signal which is close to zero and interpolates for each GPR trace data.

After time zero correction is successfully done, the next process is dewowing which aims to eliminate noise and DC bias components. Fig. 9 presents the GPR data profile after dewowing process. Fig. 10 and Fig. 11 successively presents a 1D plot for the signal trace after dewowing process and the signal amplitude ratio before and after dewowing process.

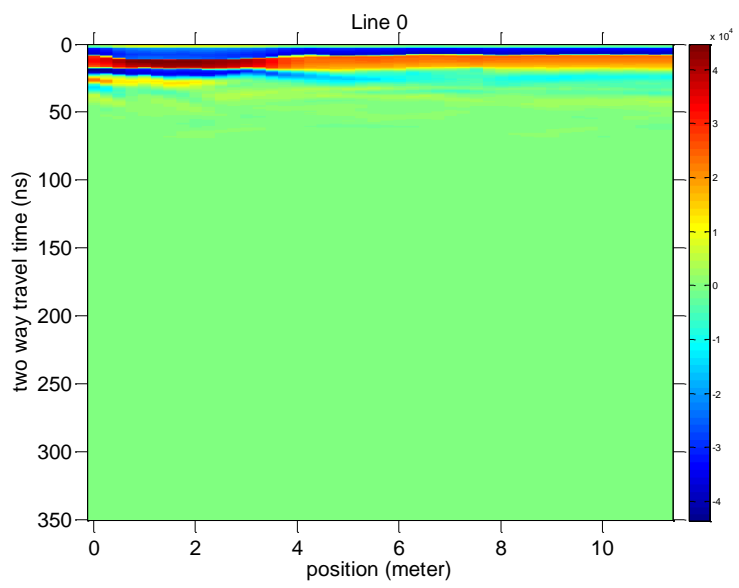

Fig. 9. GPR data image after dewowing.

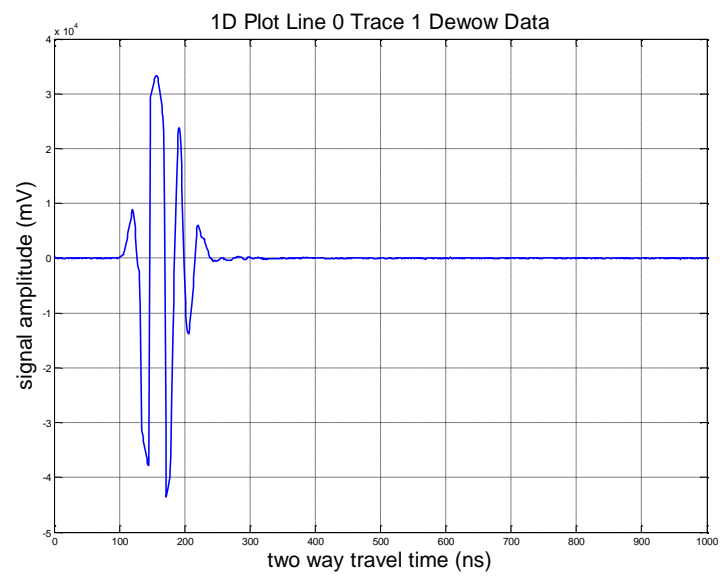

Fig. 10. GPR trace data image 1D plot after dewowing.

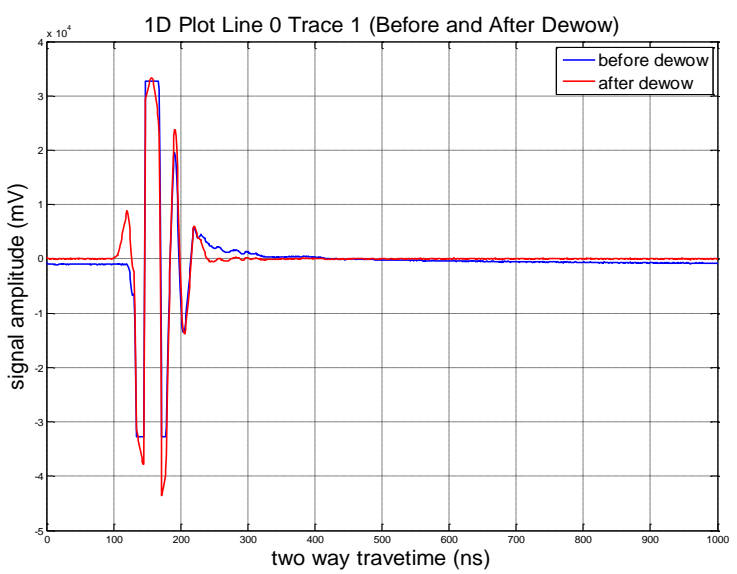

Fig. 11. Comparison of trace data images ratio of 1D plot before and after dewowing.

\section{Increasing Gain on Data}

Radar waves that propagating through the ground will getting muffled quickly. It means that the deeper the radar or electromagnetic wave propagates, the weaker signal power which causes us can not "view" more when the signal bounces below the surface and arrives at the surface. One of the ways to make the signal which has propagated deeper 
can be seen or read is strengthened them by multiplying the signal with a certain amplifier factor. This called as gain the data. There are two methods that used in this study, the first method is to increase the power of signal data with a large factor for signals that originating from the deeper subsurface and multiplying it with a smaller factor for signals coming from the subsurface that are not too deep. This method is called time power amplitude gain correction. With this first method, the GPR data image on the top layer will be a little unclear, but the bottom layer will be strong enough. The other method is to multiply all signals from all layers at various depths with the same specific factors. This method called as automated gain control. The choice of this strengthening data signal power method depends on the type of data or target that wanted to.

Time-power gain (TPOW): In the time power amplitude gain correction method, the signal is amplified along the axis of the two-way propagation time and multiplies each trace with the power of $t\left(\mathrm{t}_{\alpha}\right)$. If we assume $\alpha=1$, then we increase signal power linearly at each propagation time. If we assume $t=2$, then the power will increase quadratically throughout the propagation time. In this picture below, we use $\alpha=2$.

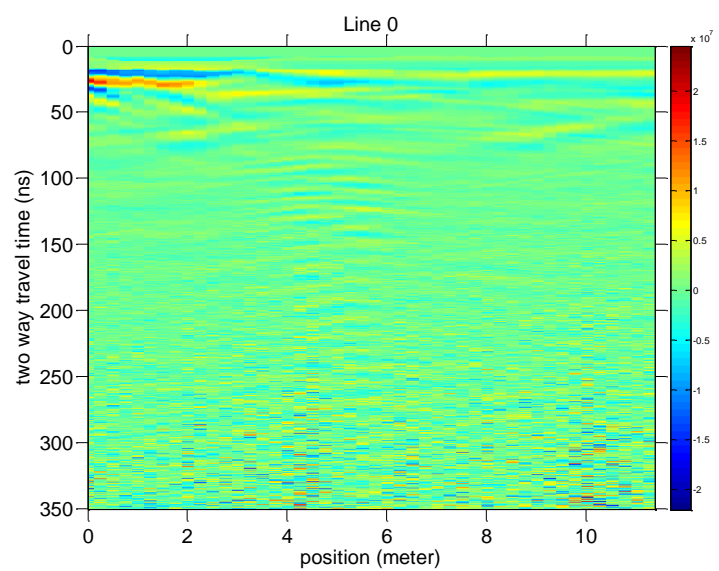

Fig. 12. Image profile of GPR data after being strengthened by the time power gain method.

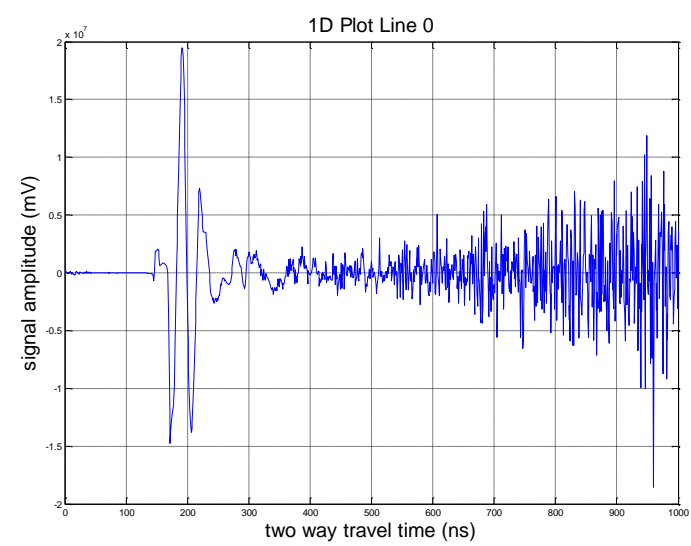

Fig. 13. 1D plot for signal trace after being strengthened by the time power gain method.

Fig. 12 presents an image that similar to the image after the dewowing process. The difference can be seen on the deeper surface. In the picture with the time power method, the profile data on the upper surface does not change too much, but the signal conditions only weaken, while there is a difference at the bottom because the signal on the lower profile is stronger. Strengthening the amplitude signal at the bottom of the profile and attenuating the signal amplitude at the top of the profile is shown in Fig. 13. As seen in Fig. 13, the more located under the profile, the bigger signal strength can be gained.

Automated gain control ( $A G C)$ : The profile result of GPR data processing by increasing gain data using the automated gain control method can be seen in Fig. 14. The way to do that all is by setting up a time (depth) window and the power in each window to be the same. Therefore, we highly need to assign the window width. In each window, will be given the same strengthen for all. Fig. 15 shows the same strengthen for each window.

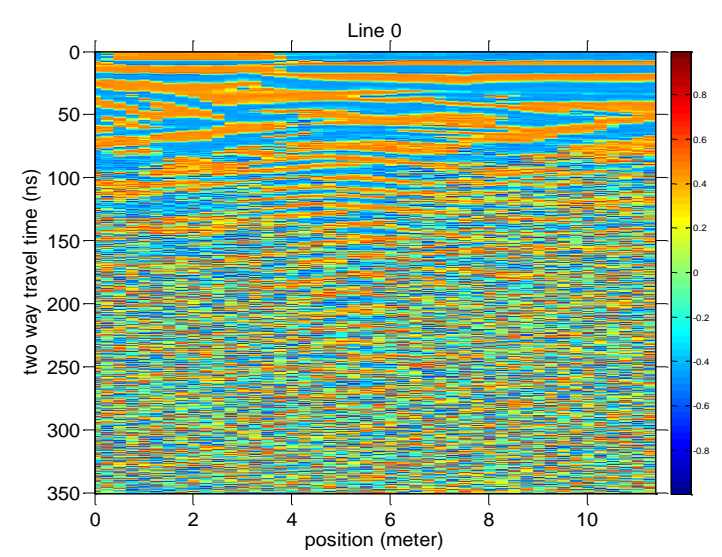

Fig. 14. Image profile of GPR data after being strengthened by the automated gain control method.

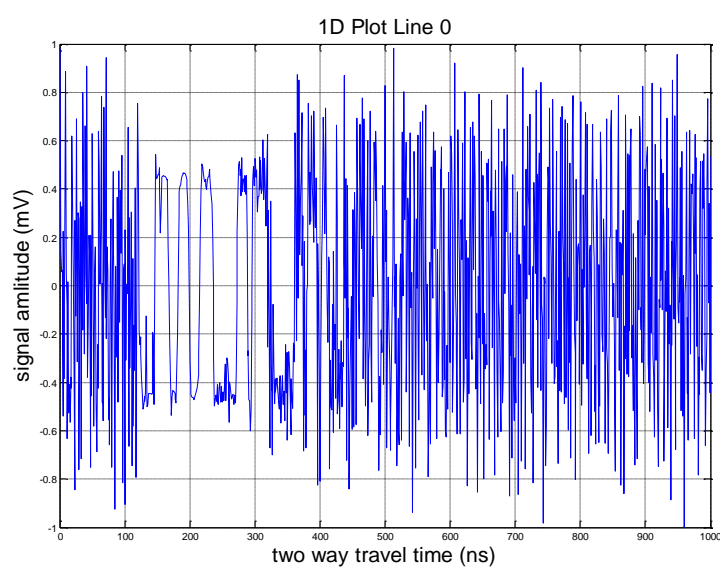

Fig. 15. 1D plot for signal trace after being strengthened by the automated gain control method

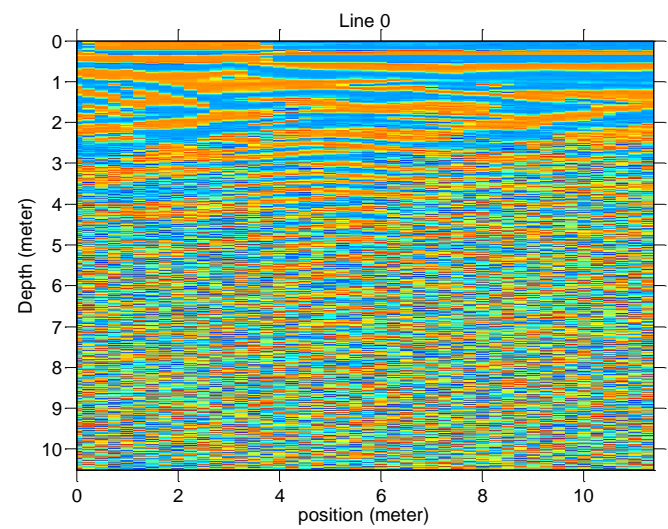

Fig. 16. Profile of GPR data images with two-way travel time converted to depth with velocity $=0.06 \mathrm{~m} / \mathrm{ns}$. 
The profile pictures that have been described before, all images are presented in two-way travel time. This two-way travel time can be converted to a depth. To convert the twoway travel time to depth, the speed of the radar signal in the ground needs to be known first. For the speed of electromagnetic waves in the media can be seen in Table I. The speed of propagation used in GPR data is $0.6 \mathrm{~m} / \mathrm{s}$. Fig. 16 showing the GPR data profile where two-way travel time is converted to depth.

\section{CONCLUSION AND FUTURE WORKS}

The goal of this study is to provide a free program to process and visualize the GPR data. This program is still under development. This program in this study follow the phase to processing GPR data as in [3], start with preparing the data, dewow, time zero correction, filtering, deconvolution, velocity analysis, elevation correction, migration and depth conversion. And the result of this phase can be seen at this paper.

Next step of this study is to convert it into freeware program so that this program can use to many other people. Our plan is to convert it into Octave Program.

\section{ACKNOWLEDGMENT}

The authors wish to thank to Head of Institute of Research and Community Service, Universitas Negeri Jakarta and Head of DJA Institute which funding this research.

\section{REFERENCES}

[1] K. Budiono, Handoko, and U. Hermawan, "Penafsiran struktur geologi bawah permukaan di kawasan semburan lumpur sidoarjo berdasarkan penampang Ground Penetrating Radar (GPR)," J. Geol. Indones., vol. 5, pp. 187-195, 2010.

[2] E. Huber and G. Hans, "RGPR - An open-source package to process and visualize GPR data," in Proc. 2018 17th International Conference on Ground Penetrating Radar (GPR), 2018, pp. 1-4.

[3] H. M. Jol, Ground Penetrating Radar Theory and Applications, Oxford: Elsevier Science, 2008.

[4] Y. Erdogan, Parametric Study and Design of Vivaldi Antennas and Arrays, Ankara, Turki: Middle East Technical University, 2009.

[5] P. J. Gibson, "The vivaldi aerial," in Proc. 1979 9th European Microwave Conference, 1979, pp. 101-105.

[6] T. Hariyadi and M. Mukhidin, "Studi Parametrik Antena Vivaldi Slot dengan Pencatuan Mikrostrip," in Proc. Seminar Nasional Teknologi (SENATEK), 2015, pp. 397-403.

[7] R. Rajaraman, Design of a Wideband Vivaldi Antenna Array for the Snow Radar, Kansas: University of Kansas, 1999.

[8] N. Pudova, A. Urusova, M. Shirobokov, and A. Marchkov, "Developing GPR surveys, data processing and interpretation techniques for criminal gravesites location," in Proc. 2016 16th International Conference on Ground Penetrating Radar (GPR), 2016, pp. 1-5.

[9] S. M. Shrestha, I. Arai, T. Miwa, and Y. Tomizawa, "Signal processing of ground penetrating radar using super resolution technique," in Proc. the 2001 IEEE Radar Conference (Cat. No.01CH37200), pp. 300-305.

[10] W. F. Lang and M. X. Lin, "A practical ground penetrating radar signal processing method based on wavelet transform," in Proc. 2010 Second International Conference on Communication Systems, Networks and Applications, 2010, pp. 452-455.

[11] X. Xiao, A. Ihamouten, G. Villain, and X. Derobert, "Parametric study on processing GPR signals to get a dispersion curve," in Proc the 15th International Conference on Ground Penetrating Radar 2014, pp. 575-580.

[12] Y. Shkvyrya, "Algorithm of data processing in GPR," in Proc. 2010 International Kharkov Symposium on Physics and Engineering of Microwaves, Millimeter and Submillimeter Waves, 2010, pp. 1-1.

[13] R. N. Nagashree, N. Aswini, A. Dyana, and C. H. S. Rao, "Detection and classification of ground penetrating radar image using textrual features," in Proc. 2014 International Conference on Advances in Electronics Computers and Communications, 2014, pp. 1-5.

[14] [14] C. Schmelzbach and E. Huber, "Efficient deconvolution of ground-penetrating radar data," IEEE Trans. Geosci. Remote Sens., vol. 53, no. 9, pp. 5209-5217, Sep. 2015.

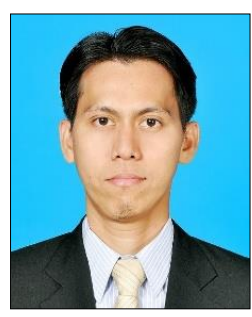

Baso Maruddani was born in Makassar, Indonesia. He completed his bachelor's degree in 2005, master's degree in 2007, and doctorate degree in 2013, all are from Institut Teknologi Bandung. Maruddani has all degrees in electronics and telecommunication fields, especially in wireless communication and signal propagation. Since 2008 to the present, he is a lecturer and researcher at Universitas Negeri Jakarta (UNJ). Aside from being a lecturer and researcher, he also became a consultant in the telecommunications sector. He once worked at Aalborg University as a researcher in the Erasmus Mundus's Mobility for Life program during 2010-2011. Dr. Baso Maruddani is also the head of DJA Institute, a foundation which engaged in education, health and ICT applications in the fields of education and health.

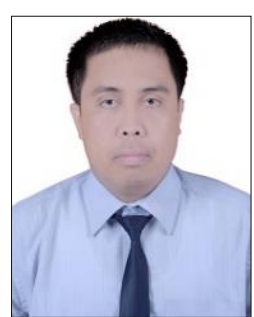

Efri Sandi was born in Rumbai, Indonesia, he obtained his bachelor's degree at Universitas Negeri Padang in 1999, his master's degree at Universitas Trisakti in 2004 and his doctorate degree at Universitas Indonesia in 2017. All of them are majoring in electronics and telecommunication, especially in antenna and propagation. Since 2008 to the present, he is a lecturer and researcher at Universitas Negeri Jakarta (UNJ). Dr. Efri Sandi also became a consultant in the telecommunication sector. Many projects related telecommunication field are handled by him. 
Neural Network Algorithm and Application 
